\title{
Assessment of the Real Estate Market Value in the European Market by Artificial Neural Networks Application
}

\author{
Jasmina Ćetković, ${ }^{1}$ Slobodan Lakić, ${ }^{1}$ Marijana Lazarevska, ${ }^{2}$ Miloš Žarkovićc $\left(\mathbb{D},{ }^{3}\right.$ \\ Saša Vujošević, ${ }^{1}$ Jelena Cvijović, ${ }^{4}$ and Mladen Gogić ${ }^{5}$ \\ ${ }^{1}$ Faculty of Economics, University of Montenegro, 81000 Podgorica, Montenegro \\ ${ }^{2}$ Faculty of Civil Engineering, University of Ss. Cyril and Methodius, 1000 Skopje, Macedonia \\ ${ }^{3}$ Erste Bank AD Podgorica, 81000 Podgorica, Montenegro \\ ${ }^{4}$ Economics Institute, 11000 Belgrade, Serbia \\ ${ }^{5}$ Faculty of Civil Engineering, University of Montenegro, 81000 Podgorica, Montenegro
}

Correspondence should be addressed to Miloš Žarković; milos.zarkovic87@gmail.com

Received 22 August 2017; Accepted 17 December 2017; Published 29 January 2018

Academic Editor: Luis Braganca

Copyright (C) 2018 Jasmina Cetković et al. This is an open access article distributed under the Creative Commons Attribution License, which permits unrestricted use, distribution, and reproduction in any medium, provided the original work is properly cited.

Using an artificial neural network, it is possible with the precision of the input data to show the dependence of the property price from variable inputs. It is meant to make a forecast that can be used for different purposes (accounting, sales, etc.), but also for the feasibility of building objects, as the sales price forecast is calculated. The aim of the research was to construct a prognostic model of the real estate market value in the EU countries depending on the impact of macroeconomic indicators. The available input data demonstrates that macroeconomic variables influence determination of real estate prices. The authors sought to obtain correct output data which show prices forecast in the real estate markets of the observed countries.

\section{Introduction}

The difficulty or impossibility of constructing an overall model with potential reactions and counterreactions (participants or agents) stems from the complexity of social, economic, and financial systems. It is assumed that the methodology of the neural network with evident complexity of the system, the usual incomprehensibility and general impracticality of the model, can help to emulate and encourage the observed economy or society. The problem is more obvious if one tries to control all possible variables and potential results in the system as well as to include all their dynamic interactions [1]. The application of artificial neural networks as well as econometric models is characterized by specific advantages and disadvantages. Nevertheless, neural networks have been imposed as a real alternative to econometric methods, that is, as a powerful tool for assessment and forecasting, for example, in the field of evaluating real estate. It is specially emphasized that it is possible to find estimated values instead of exact values.
Artificial neural networks are relatively new computer tools that are widely used in solving many complex real problems. Their attractiveness is a product with good characteristics in data processing, tolerance of input data errors, high learning opportunities on examples, easy adaptation to changes, and generalization of the methodology for developing successful artificial neural networks starting with conceptualization projects, through design projects, to implementation projects [2]. The use of artificial neural networks for forecasting has led to a vast increase in research over the past two decades [3].

A generation of various prognostic models is based on the use of artificial neural networks, which are recently being studied as a contemporary interdisciplinary field at many universities, which help solve many engineering problems that cannot be solved using traditional methods. Researched neural networks are used successfully as an analytical tool for relevant forecasts that greatly improve the quality of decisionmaking at various levels. The common problem of successful applications of artificial neural networks in forecasts and 
modeling is related to the lack of necessary data-the data available is "noisy" or incomplete and the circumstances that the quantities being modeled are governed by multivariate interrelationships [4]. On the other hand, a large number of studies point to the fact that prognostic models obtained by the use of artificial neural networks exhibit a satisfactory degree of accuracy and are particularly useful in situations for preperformed numerical or experimental researches [5]. The use of these models has been explored and demonstrated reliability in a large number of applications in construction [6-11].

The wide scientific and technical use of neural networks in the conditions of increased complexity of the market, when they show superiority (effectiveness) in an unstable environment, is acceptable to analysts, investors, and economists despite the shortcomings. The multidisciplinarity of neural networks and their complexity coverage makes them suitable for assessing market variables, that is, underlying, indexed, and derivative financial instruments. Comparing the instability of forecasts obtained using neural networks with the encompassed volatility of the S\&P Index futures options and applying the BAW pricing model of options to futures, Hamid concluded that forecasts from neural networks are better than the implied instability forecasts and slightly different from the realized volatility [12].

Models of artificial neural networks provide reasonable accuracy for many engineering problems that are difficult to solve by conventional engineering approaches of engineering techniques and statistical methods $[13,14]$. The application of artificial neural networks in the construction sector is of great importance and usable value. Recent literature suggests that the methodology of neural networks is largely used to model different problems and phenomena in the field of construction [15-20].

Artificial neural networks are useful for modeling the relationship between inputs and outputs directly on the basis of observed data. As already noted, they are capable of learning, generalizing results, and responding to highly expressed incompleteness or incompleteness of available data [21]. As artificial neural networks have better performance than multivariate analysis because they are nonlinear, they are able to evaluate subjective information difficult to include in traditional mathematical approaches. Furthermore, the prominent abilities of neural networks are particularly evident in complex systems such as the real estate system, where in recent years artificial neural networks are widely used to create a model for estimating prices in real estate markets. A number of such models have been published in scientific and professional literature. Thus, in the last decade of the 20th century, Borst defined a number of variables for the design of a model based on artificial neural networks to appraise real estate in New York State, demonstrating that the model is able to predict the real estate price with $90 \%$ accuracy [22].

\section{Materials and Methods}

The problem of assessing the market value of real estate in construction has always been current from the angles of both the real estate buyers and sellers/investors and in particular for future investments. Therefore, in theory and practice, there are various methods for determining the market value of real estate. Given that the market value of a property is influenced by a large number of factors, the process of estimating the real estate market is quite complex and is always current again. A negative assessment practice that only confirms the agreed real estate price is lighter but less precise and can lead to deviations of estimated value from the real market value of real estate [23]. As part of traditional methods of estimation derive from the impact of objective factors on the real estate price, neglecting the undeniable influence of subjective factors that have a significant impact on the price of real estate, generalization of the application of these methods is not possible because the real estate market in different countries is influenced by various objective and subjective factors. The hedonistic real estate assessment method, based on a multiple regression analysis, though often used to test new estimation methods, is burdened by initial assumptions and is not sufficiently rational to evaluate $[23,24]$.

With the development of new computer and mathematical modeling methods, the trend of developing new approaches for real estate market assessment is notable. Namely, the use of artificial neural networks has proved to be justified in the development of unconventional methods for assessing real estate market value which enable a more objective and more accurate estimate of real estate in the market. As the valuation process is always a problem in free market economies, market participants usually do not have complete and accurate pricing information which is why they are considering a variety of factors and different relationships between them. In the real estate market, there is usually a more pronounced lack of accurate information compared to information about another commodity because data is usually not available in a consistent format. Analysis and interpretation of general trends are hampered by the sparse variety of characteristics/properties of these commodities, usually related to a particular location [25]. Therefore, a large number of authors elaborated other approaches as an alternative to the conventional method of assessment and developed new models for assessing the market value of real estate that are capable and usable for similar purposes [26-28].

Developed models of artificial neural networks have shown that residential property markets are under the influence of different economic and financial environments. The aim of developing such models is to indicate, inter alia, whether the economic and financial situation of the observed countries reflects the general economic situation on the real estate market. The results showed that the economic and financial crisis in these countries had different impacts on real estate prices [29]. The methodology based on rough set theory and on artificial neural networks proved to be suitable for the convergence of residential property prices index $[29,30]$. During the last decade, the literature analyzed the impact of property price volatility on the economy in general: unemployment, consumer confidence in government, banking practices, and social costs. On the other hand, the macroeconomic situations, such as the business cycle, employment rates, income growth, interest rates, inflation rates, loan supply, returns on real estate investments, and 
other factors, such as population growth, have had a significant impact on housing prices.

Contrary to the dominant application of multiple regression models, involving human estimations, the use of artificial neural networks, the model of artificial intelligence, allows the hidden nonlinear connections between the modeled variables to be uncovered. In the context of neural networks, a special place was occupied by the so-called backpropagation models. These neural networks contain series of simple interconnected neurons (or nodes) between the input and output vectors. Pi-Ying used a backpropagation neural network as a tool for constructing a housing price model for a selected city [31]. The paper investigates the importance of the application of neural network technologies in the real estate appraisal problem. Starting from the consequences of the nature of the neural network model, Pi-Ying concludes that the model creates a larger prediction error compared to multiple regression analysis. However, by estimating a large number of real estate properties, Peterson and Flanagan found that artificial neural networks, compared to linear hedonic pricing models, create significantly minor errors in dollar pricing and have greater out-of-sample precision and there is a better extrapolation in a more volatile environment [32].

According to Limsombunchai (2004), the hedonistic cost model and the artificial neural network emphasized that the hedonistic technique is generally unrealistic in dealing with the housing market in any geographic area as a single unit. Compared to neural network models, this model shows poorer results in the out-of-sample prediction [33]. Market imperfections, complemented by bid rigidity and heterogeneity of quality, contribute to the deviation of real estate prices from the fundamental value. Consequently, under sustainable deviation conditions, the problem of adverse selection is spurred, and, in the periods of financial liberalization and the boom-bust cycle, the consequence (distortion) is moral hazard [30]. The empirical and operational framework suggests that the residential property market directly determined the magnitude of the economic growth.

European economic growth is supported by the expanded ECB stimulus (quantitative easing), which has increased liquidity, confidence, and domestic consumption by creating a fundament that impacts the real estate market. Growth, that is, the boom of house prices in Europe, shows continuity lately. This can be tracked over the momentum which is increasing if the property market grows faster this year compared to the previous (or fall below). Therefore, this is a "change in change" measure which shows that most of the housing market is slowing down, although the boom continues strongly in Europe [34]. The factor that has affected the European housing market is GDP growth. In the beginning of the previous decade, the correlation between lagging in GDP growth and house prices in the $\mathrm{EU}$ was $81 \%$. According to these analyzes, the expected sluggish growth of the economy should limit the growth of apartments prices in the coming years.

Interest rates, as another economic indicator of the real estate market, depend on monetary policy in the ECB and other central banks in the EU. Low interest rates are the result of expansive monetary policy which stimulates the real estate market. There is a correlation of residential lending and house prices. The rise in house prices is a consequence of the growth of residential lending, and as a result of price rises, the ratio of resident debt to household disposable income is changing. This indebtedness of households along with the household debt capacity becomes a determinant of the rise in house prices. There are two consequences of cheap residential housing in the European Union (2015): the rapid rise in property prices in certain markets and the great difference in transaction prices between cities and countries [35].

Housing is not only an important segment of household wealth but also a key sector of the real economy. The decline in housing construction can be reflected negatively (directly or indirectly) on financial stability and the real economy. In addition, the role of the loan is significant in the rise and recession of housing. Financial and macroeconomic stability are significantly affected by the development of the residential real estate sector. The main responsibility of macroprudential authorities is to analyze the vulnerabilities of this market. In the EU, European Systemic Risk Board has the mandate to implement "macroprudential oversight of the financial system within $\mathrm{EU}$ in order to contribute to the prevention or mitigation of systemic risk." The ESRB identifies countries in the EU that have medium-term sensitivities that can be the cause of systemic risk and result in serious negative consequences. Horizontal analysis based on key indicators, risk analysis, and analysis of structural and institutional factors (vertical) are implemented [36].

In this paper, a model for estimating real estate prices in 27 European countries has been defined. This research paper indicates the author's assumption was aided by a prognostic model using artificial neural networks with the available factors influencing the real estate price formation. These factors can obtain accurate real estate prices in the European market which can have a significant value in the decisionmaking process of buying real estate in the European market.

Otherwise, in literature there are various approaches to the division of factors that more or less influence the formation of prices in the real estate markets. One of the usual divisions is on macroenvironment factors (e.g., exchange rate, employment, GDP, loan interest rate, and geofactors) and microenvironment factors (mostly related to construction environment) [37]. In addition to this division, there is a division of factors into rational ones related to the real price of real estate and irrational ones that reflects the expectation of consumers [38]. At the same time, certain analysis has highlighted the fundamental real estate factors in any country in relation to loan availability, housing supply and dimet ratio, interest rate decrease, changes in housing market participants' expectations, administrative restrictions of supply, and so forth [39].

For the purpose of developing a prognostic model for the European real estate market, based on artificial neural networks, the authors suggested macroeconomic factors affected the real estate market. Training of the artificial neural network was carried out by defining 11 inputs and one output of the network (house price). The output variables-real estate prices for $27 \mathrm{EU}$ countries-are provided on the basis of 
available empirical data [36] and certain authors' calculations. Table 1 shows the basic inputs into the model and their definition and basic characteristics. Precollection and data analysis, preparation of data for defining the model, and, ultimately, the production of the model were performed.

The basic characteristics of the input and output parameters used for the training network represent 253 sets of data of which $80 \%$ are selected as a network training set and $20 \%$ as a validation set. All data is downloaded from the abovementioned databases. After training the network was controlled on 11 sets of data on which the network was not trained.

The market value of real estate is subject to time changes and is determined at a certain date, so this prognostic model is time-dependent.

Creating an artificial neural network model trained to solve this problem consisted in defining network architecture with 11 variable inputs and one output. For network training, a two-layer neural network with two hidden layers of 15 neurons in the hidden layer was adopted.

Network training was conducted on a nonrecurrent network, while network training was carried out using an improved Backpropagation algorithm by periodically passing data from a training session through a neural network. The values obtained were compared with the actual outputs, and if the difference was made, correction of weight coefficients was made. Correction of weighing coefficients of the network was done by the rule of gradient downhill:

$$
w_{i j}^{(l) \text { new }}=w_{i j}^{(l) \text { old }}-\eta \frac{\partial \varepsilon_{k}}{\partial w_{i j}^{(l)}}
$$

As an activation function, a logistic sigmoidal function was used:

$$
f(x)=\frac{1}{1+e^{-x}}
$$

Improving the Backpropagation algorithm meant introducing a moment so that the weight change in the period $t$ would depend on the change in the previous period:

$$
\Delta w_{i j}^{(l)}(t)=-\eta \frac{\partial \varepsilon_{k}}{\partial w_{i j}^{(l)}}+\alpha \Delta w_{i j}^{(l)}(t-1), \quad 0<t<1 .
$$

Network training was selected for a validation set of $20 \%$ of data. Training went to the moment of an error in the validation set so that the trained network showed good forecast performances.

The neural network is trained within the MS Excel program. Minor deviations from the training session are noted. Based on the network initiation with the input data from the range of data used in training, it is possible to draw up prognostic models of the dependence of the output from any input.

Control forecast was performed on 11 test datasets on which the network was not trained.

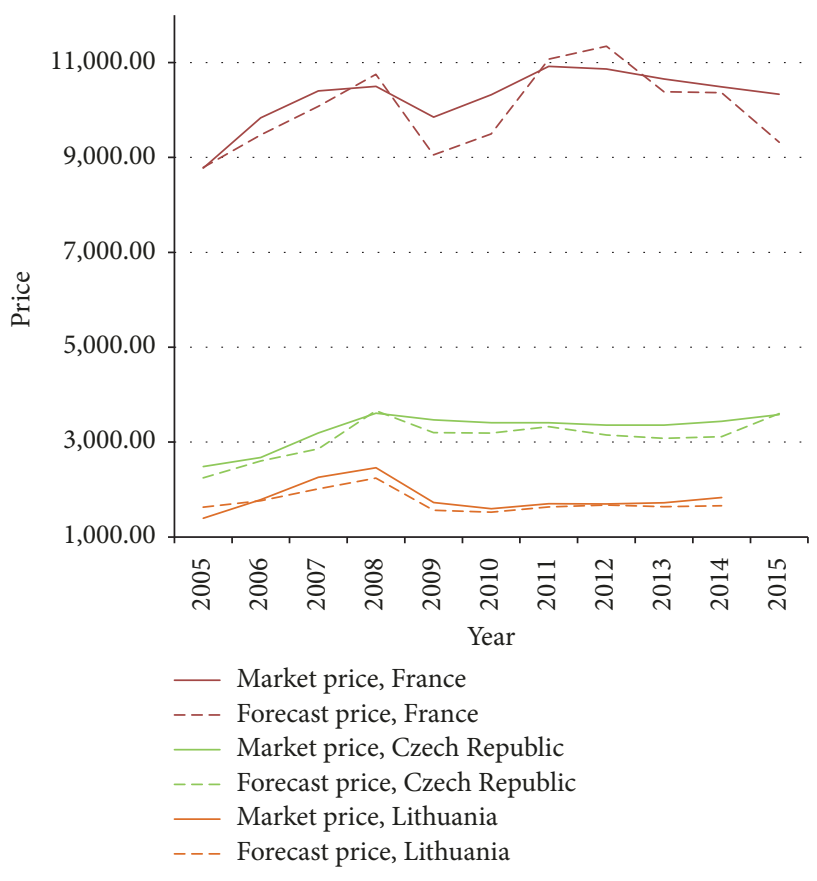

FIGURE 1: Deviation of the real price from the price forecast.

\section{Results and Discussion}

In general, our research has shown that prognostic models, based on the use of artificial neural networks, have a satisfactory degree of precision. Namely, the prognostic model for estimating the price of the real estate in the EU market, done for the purposes of this survey, is an average deviation of real price from a price forecast of up to $14 \%$. Figure 1 shows this deviation for 3 selected countries of different level of development.

On the basis of the prognostic model, designed on the use of artificial neural networks, real estate prices in the EU countries were estimated, starting with the macroeconomic variables that were originally assumed to have a significant impact on the output variable. The analysis takes into account the impact of the change of a certain factor relevant to real estate prices in the EU market, with other unchanged real variables.

Figures 2, 3, and 4 show changes in forecasted real estate prices in countries with different levels of development (high, medium, and low) under the influence of GDP growth rates. In the countries surveyed, regardless of the degree of development, there is a trend of growth of forecasted real estate prices with an increase in the GDP growth rate. Theoretically, GDP growth rate can significantly increase the real estate price by increased consumption in the conditions of large housing infrastructure projects that are affecting employment growth. Mortgage payments are more acceptable, so real estate demand rises and ultimately increases real estate prices. Some research deals with the relationship between changes in real estate prices and changes in real GDP, or whether the interdependence between these two variables is statistically significant. The regression analysis method has indicated that 


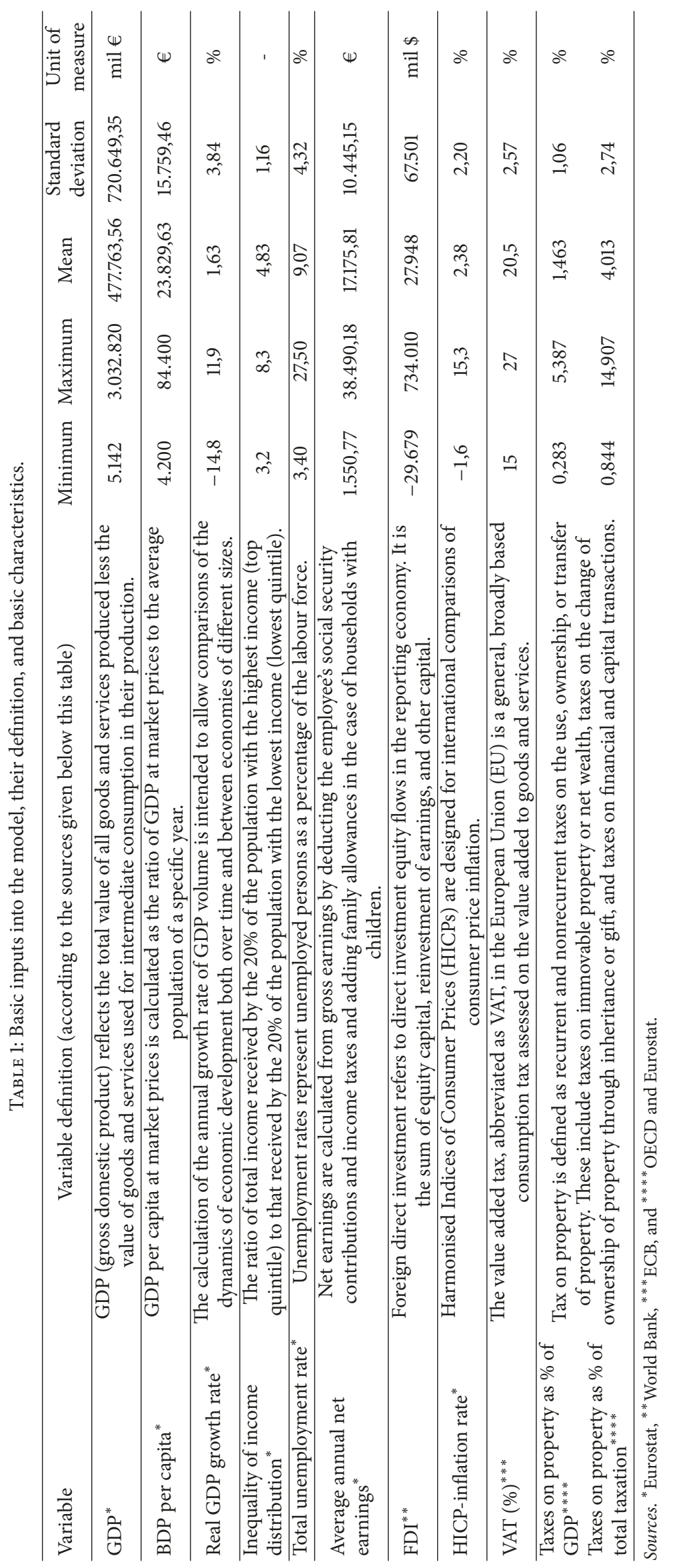




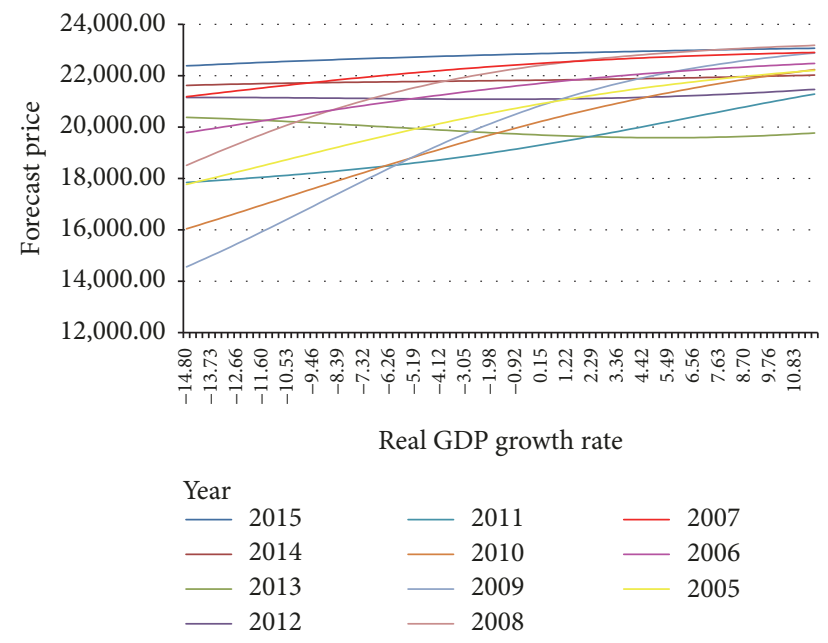

FIGURE 2: The impact of the real GDP growth on the real estate price forecast in the UK.

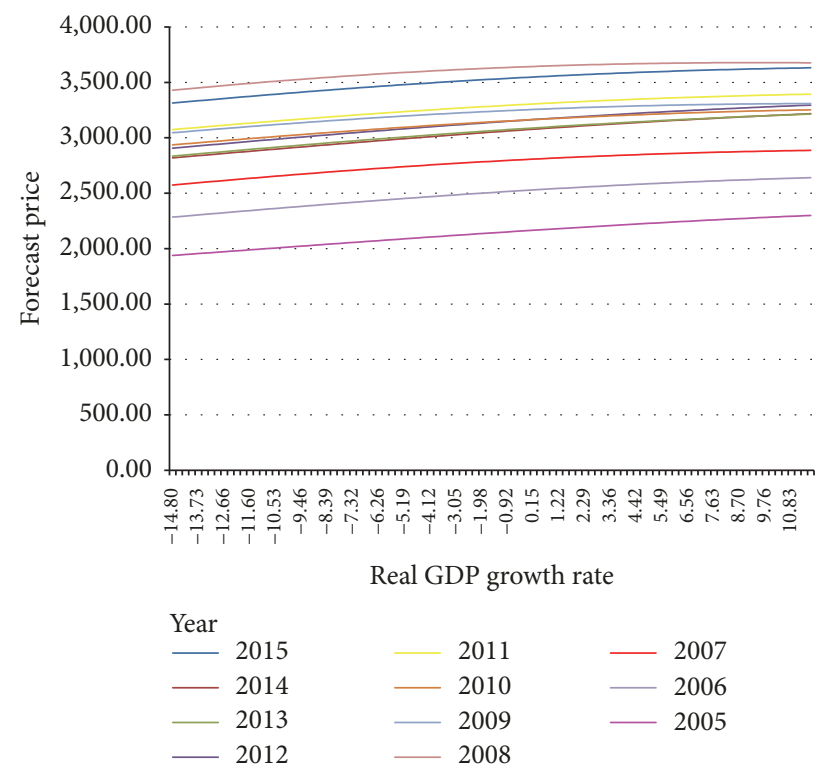

FIGURE 3: The impact of the real GDP growth rate on the real estate price forecast in Czech Rep.

there is a relationship and dependence, while the correlation suggests a possible causal interconnection between these variables [40]. In OLS (ordinary least squares) models, as well as in models based on the application of artificial neural networks, the GDP growth rate is taken as one of the key macroeconomic variables that affect the price of real estate with varying degrees of significance in different countries [29].

Figures 5, 6, and 7 show changes in the real estate prices forecast under the influence of the HICP. On the figures, it can be seen that, regardless of the degree of development of the country with the increase in HICP, there is a rise in the forecasted price of real estate. Some studies, such as those from Burinsena, Rudzkiene, and Venckauskaite, on the example of Lithuania, have shown that the HICP, as

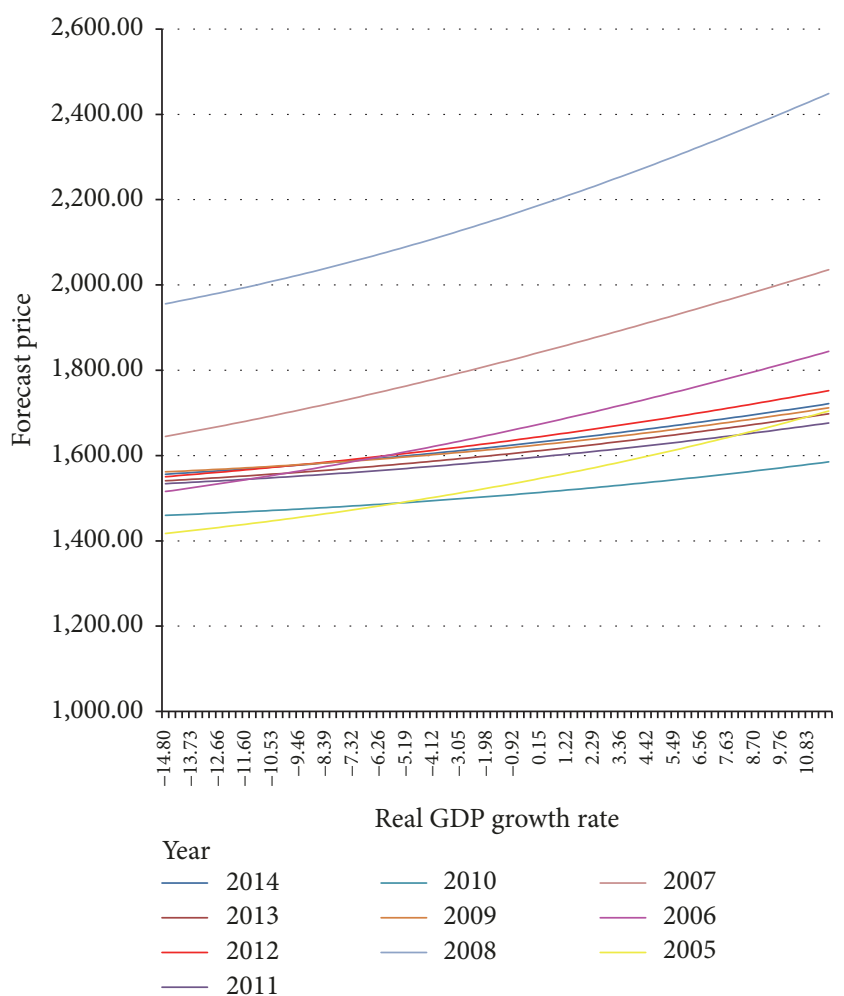

FIGURE 4: The impact of the real GDP growth rate on the real estate price forecast in Lithuania.

an indicator of the average annual inflation rate, is one of the main factors of the real estate market [39]. Also, some research conducted for highly developed countries (e.g., Norway case) have shown that a long-term increase in HICP has been accompanied by a rather sharp rise in real estate prices [41].

Figures 8,9 , and 10 show changes in the real estate prices forecast under the influence of the unemployment rate in countries with different levels of development. Figures for the surveyed countries indicate an apparent decline in the real estate prices forecast with an increase in the unemployment rate. In theory, the dominant views are that low unemployment leads to an income rise and affects the increase in consumer confidence that manifests itself on the real estate market, encouraging real estate prices growth and vice versa. Earlier empirical research on the impact of economic variables on property price dynamics has shown that growth in unemployment reduces real estate prices [42], as our prognostic model also pointed out. Certain recent empirical studies point to the undeniable impact of the unemployment rate, as a macroeconomic factor, on real estate prices. The impact of the unemployment rate on real estate prices differs from country to country. One of these studies has shown that the price of real estate in France, Greece, Norway, and Poland is statistically significantly associated with unemployment [43]. Also, research related to Ireland proves that at low levels of unemployment, real estate prices tend to grow [44].

Figures 11, 12, and 13 show changes in real estate prices forecast in countries with different levels of development 


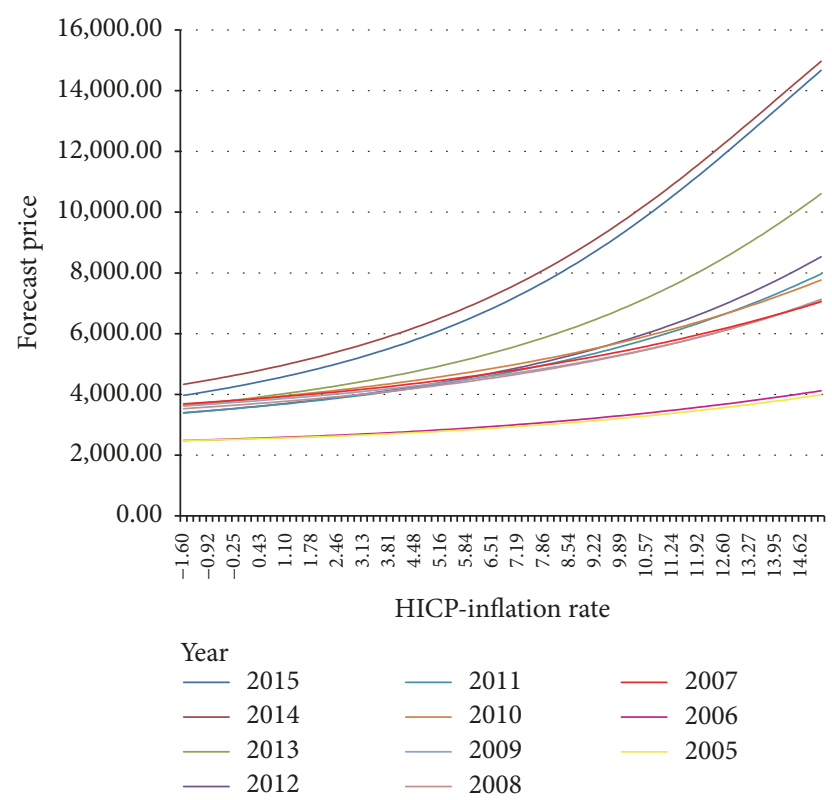

FIgURE 5: The impact of the HICP-inflation rate on the real estate price forecast in Germany.

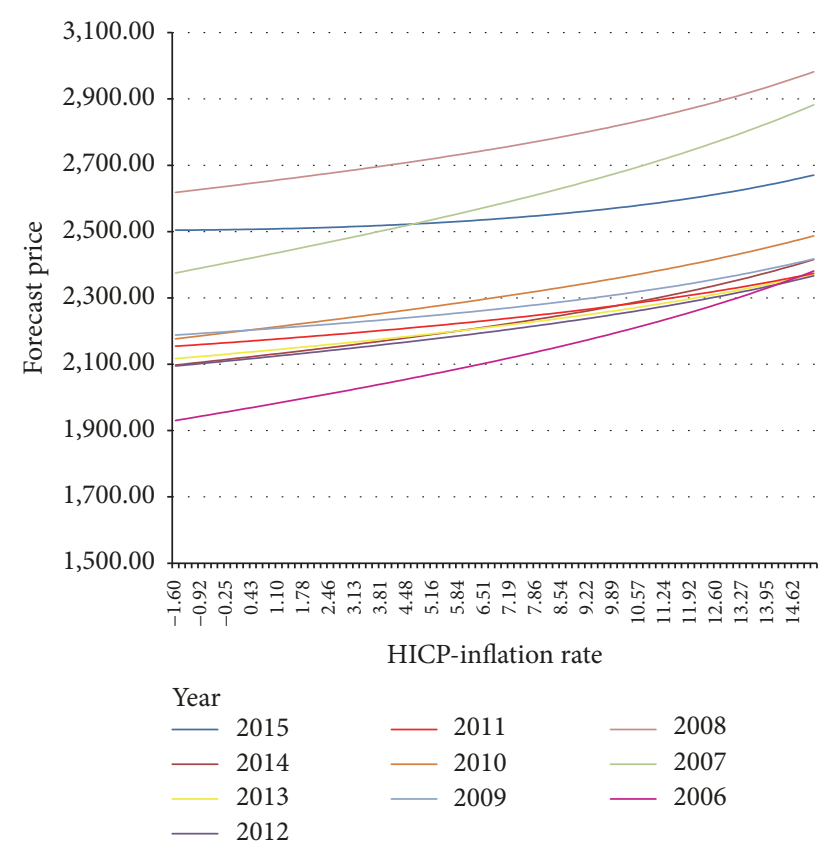

FIGURE 6: The impact of the HICP-inflation rate on the real estate price forecast in Slovakia.

(high, medium, and low developed) under the influence of average annual net earnings. The growth of average annual net earnings is followed by the growth of the output variable-real estate prices in the observed countries. Empirical researches have shown during the previous decades that the growth rate of income (earnings) is an essential determinant of the growth of real estate prices. Thus, in highly developed countries, income growth (earnings), at lower interest rates and slower lending conditions, is recognized

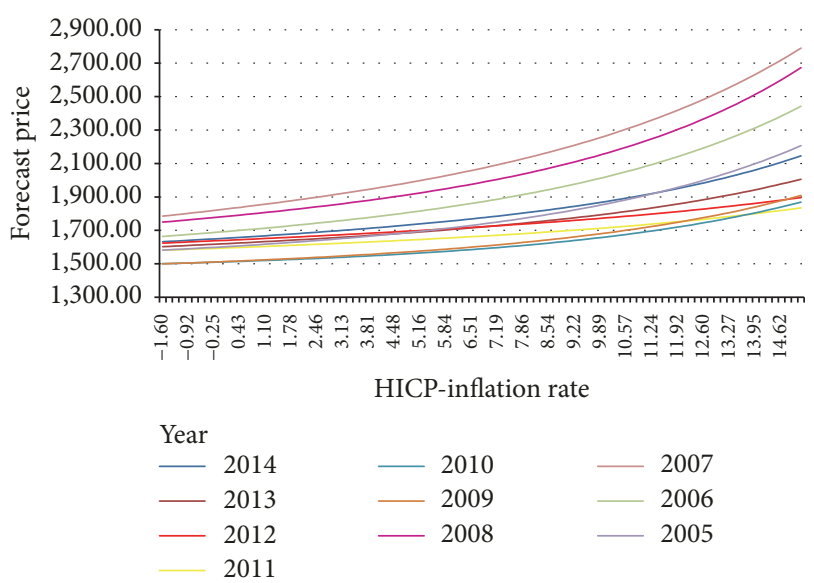

FIgure 7: The impact of the HICP-inflation rate on the real estate price forecast in Lithuania.

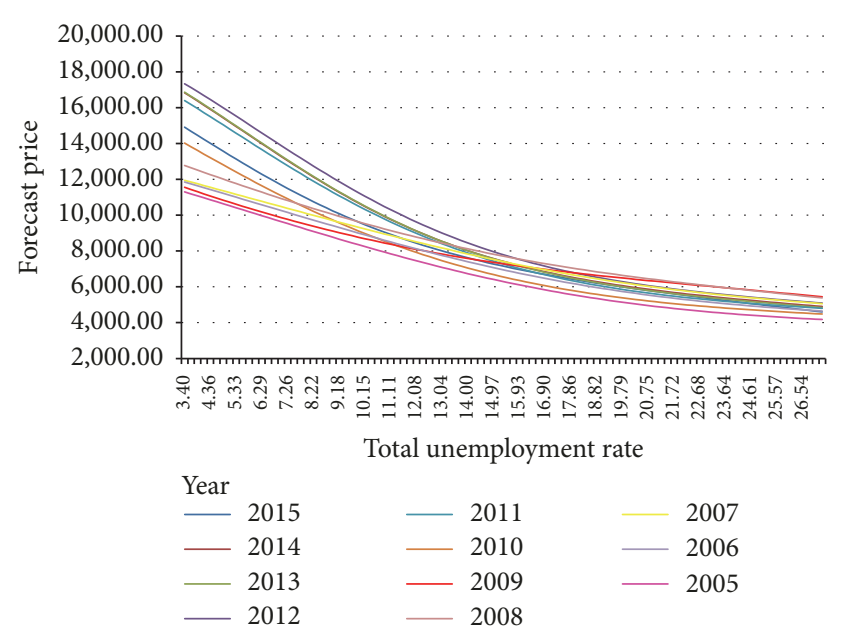

FIGURE 8: The impact of the total unemployment rate on the real estate price forecast in France.

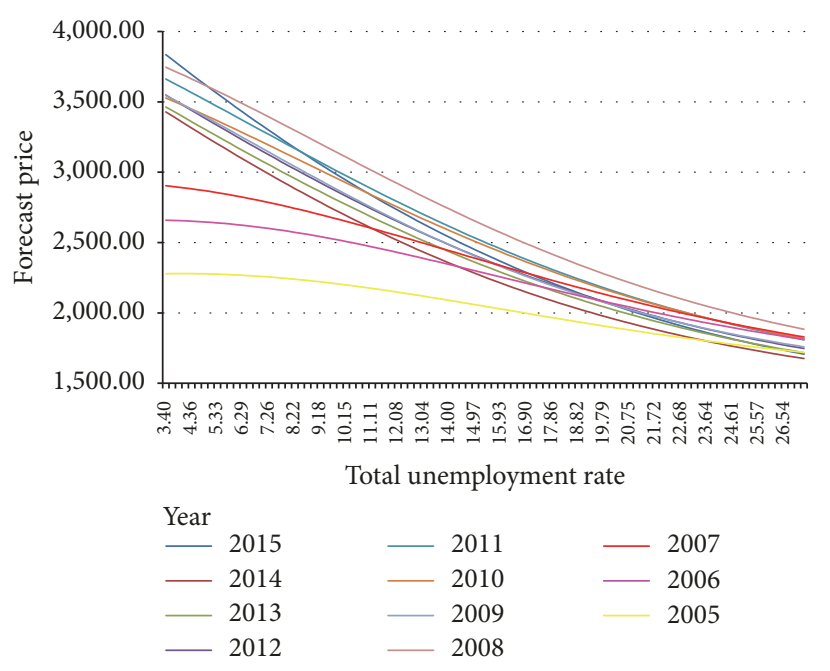

FIGURE 9: The impact of the total unemployment rate on the real estate price forecast in Czech Rep. 


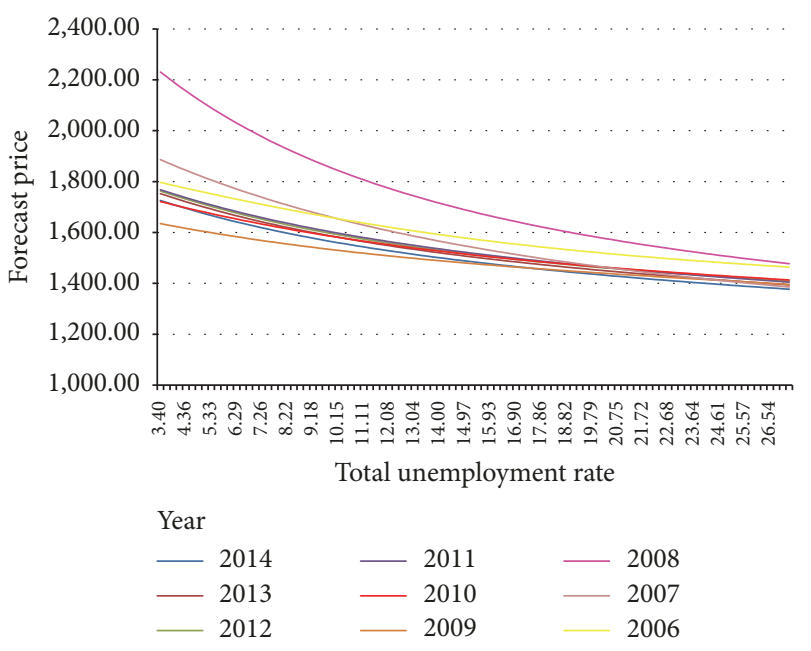

FIGURE 10: The impact of the total unemployment rate on the real estate price forecast in Bulgaria.

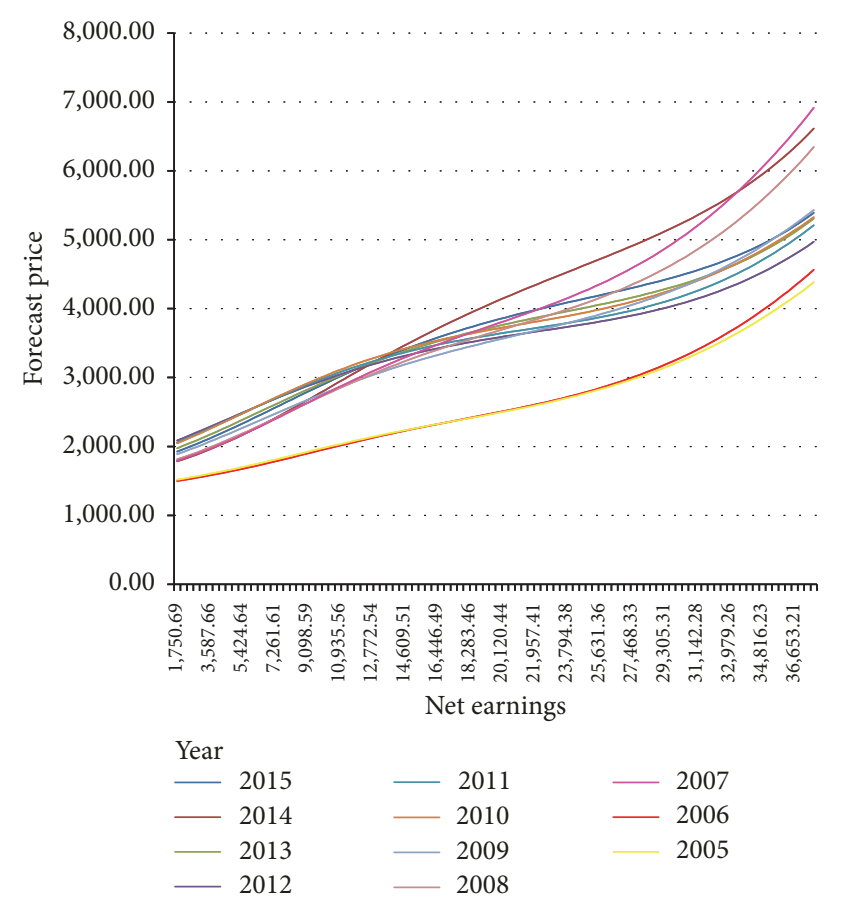

FIGURE 11: The impact of net earnings on the real estate price forecast in Germany.

as a key factor in the rapid rise of the real estate prices [45]. Certain models, such as the P-W model, indicate that house prices are functions of the cyclical unemployment rate, income, demographics, costs of financing housing purchases, and costs of construction materials [46].

\section{Conclusion}

The economic and social importance of the real estate market corresponds to overall economic development, but the housing sector can also be the cause of vulnerability and

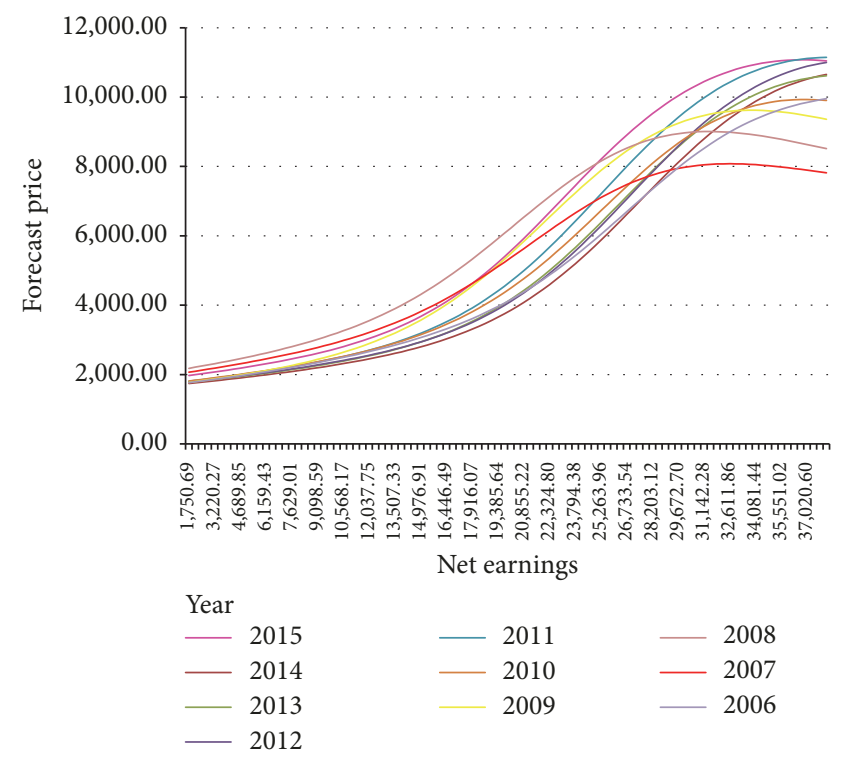

FIGURE 12: The impact of the net earnings on the real estate price forecast in Slovakia.

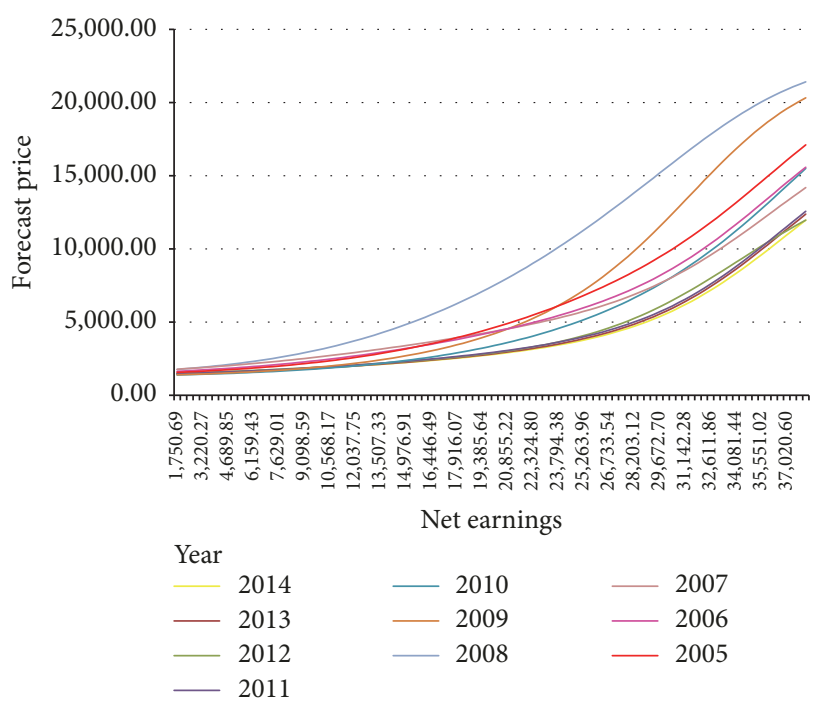

FIGURE 13: The impact of the net earnings on the real estate price forecast in Lithuania.

crisis. Therefore, the problem of estimating the value of real estate is always current and complex due to the influence of a large number of variables that are recognized in the literature as usual as macroeconomic, construction, and other factors. Contrary to conventional real estate estimation methods, new approaches have been developed to evaluate prices in real estate markets. In addition to the hedonic method in the last decades, models of artificial neural networks that provide more objective and accurate estimates have been developed. This paper presents a prognostic model of real estate market prices for EU countries based on artificial neural networks.

For a rough and fast estimation of house prices with a reliability of about $85 \%$, it is possible to use a trained neural network. We consider the obtained level of reliability as very 
high, it is about modeling the sociotechnical system. More accurate pricing and reliable information could be obtained if a larger set of input parameters was included.

It is shown that the neural network can model nonlinear behavior of input variables and generalize real estate prices data for random inputs in the network training range. The model shows a satisfactory degree of forecasted precision which guarantees the possibility of its applicability.

\section{Conflicts of Interest}

The authors declare that there are no conflicts of interest regarding the publication of this paper.

\section{References}

[1] Y. Shachmurove, "Business application of emulative neural networks," International Journal of Business, vol. 10, no. 4, 2005.

[2] I. A. Basheer and M. Hajmeer, "Artificial neural networks: fundamentals, computing, design, and application," Journal of Microbiological Methods, vol. 43, no. 1, pp. 3-31, 2000.

[3] G. Zhang, B. E. Patuwo, and M. Y. Hu, "Forecasting with artificial neural networks: the state of the art," International Journal of Forecasting, vol. 14, no. 1, pp. 35-62, 1998.

[4] A. W. C. Oreta and K. Kawashima, "Neural network modeling of confined compressive strength and strain of circular concrete columns," Journal of Structural Engineering, vol. 129, no. 4, pp. 554-561, 2003.

[5] M. Lazarevska, M. Knežević, M. Cvetkovska, and A. TrombevaGavriloska, "Application of artificial neural networks in civil engineering," Technical Gazette, vol. 21, no. 6, pp. 1353-1359, 2014.

[6] M. Lazarevska, M. Kneževiá, M. Cvetkovska, N. Ivaniševič, T. Samardzioska, and A. Trombeva-Gavriloska, "Fire-resistance prognostic model for reinforced concrete columns," Gradjevinar, vol. 64, no. 7, pp. 565-571, 2012.

[7] D. Bojović, D. Jevtić, and M. Knežević, "Application of neural networks in determination of compressive strength of concrete," Romanian Journal of Materials, vol. 42, no. 1, pp. 16-22, 2012.

[8] B. Šćepanović, M. Knežević, and D. Lučić, "Methods for determination of ultimate load of eccentrically patch loaded steel Igirders," Informes de la Construcción, vol. 66, no. 1, pp. 1-13, 2014.

[9] M. Knežević, M. Lazarevska, M. Cvetkovska, A. TrombevaGavriloska, and M. Milanović, "Neural network based approach for prediction the fire resistance of centrically loaded composite columns," Technical Gazette, vol. 23, no. 5, 2016.

[10] M. Knežević, D. Bojović, D. Nikolić, K. Jovanović, and L. Lončar, "The effect of entrapped air on concrete compressive strength- neural network approach and classical research," in Proceedings of the 14th International Symposium of DGKM, pp. 69-74, Struga, Macedonia, 2011.

[11] M. Lazarevska, M. Knežević, and M. Cvetkovska, "Application of artificial neural networks for prognostic modeling of fire resistance of reinforced concrete pillars," Applied Mechanics and Materials, vol. 148-149, pp. 856-861, 2011.

[12] S. A. Hamid, "Primer on using neural networks for forecasting market variables," in Proceedings of the Conference at School of Business, Southern New Hampshire University, 2004.

[13] I. Flood, "Simulating the construction process using neural networks," in Proceedings of the 7th International Symposium on
Automation and Robotics in Construction, pp. 374-382, Bristol, UK, June 1990.

[14] D. S. Jeng, D. H. Cha, and M. Blumenstein, "Application of neural networks in civil engineering problems," in Proceedings of the International Conference on Advances in the Internet, Processing, Systems and Interdisciplinary Research, 2003.

[15] A. Mukherjee and J. M. Deshpande, "Modeling initial design process using artificial neural networks," Journal of Computing in Civil Engineering, vol. 9, no. 3, pp. 194-200, 1995.

[16] M. A. Shahin, H. R. Maier, and M. B. Jaksa, "Predicting settlement of shallow foundations using neural networks," Journal of Geotechnical and Geoenvironmental Engineering, vol. 128, no. 9, pp. 785-793, 2002.

[17] A. Sanad and M. P. Saka, "Prediction of ultimate shear strength of reinforced-concrete deep beams using neural networks," Journal of Structural Engineering, vol. 127, no. 7, pp. 818-828, 2001.

[18] R. J. Abrahart and L. M. See, "Neural network modelling of nonlinear hydrological relationships," Hydrology and Earth System Sciences, vol. 11, no. 5, pp. 1563-1579, 2007.

[19] A. M. Elazouni, I. A. Nosair, Y. A. Mohieldin, and A. G. Mohamed, "Estimating resource requirements at conceptual design stage using neural networks," Journal of Computing in Civil Engineering, vol. 11, no. 4, pp. 217-223, 1997.

[20] J. Xie, J.-F. Qiu, W. Li, and J.-W. Wang, "The application of neural network model in earthquake prediction in East China," Advances in Intelligent and Soft Computing, vol. 106, pp. 79-84, 2011.

[21] J. Shaw, "Neural network resource guide," AI Expert, vol. 8, no. 2, pp. 48-54, 1992.

[22] R. A. Borst, "Artificial neural networks: the next modeling/calibration technology for the assessment community?" Property Tax Journal, vol. 10, no. 1, pp. 69-94, 1991.

[23] M. Mattos, P. Simoes, E. Zancam, N. Ferreira, and C. Cechinel, "A neurofuzzy approach for property value prediction," in Proceedings of the 35 th Conferencia Latinoamericana de Informatica (CLEI '08), 2008.

[24] D. Fischer and P. P. Lai, "Artificial neural networks and computer assisted mass appraisal," in Proceedings of the 12th Annual Conference of the Pacific Rim Real Estate Society (PRRES '06), Auckland, New Zealand, January 2006.

[25] C. Bagnoli and H. C. Smith, "The theory of fuzzi logic and its application to real estate valuation," The Journal of Real Estate Research, vol. 16, no. 2, 1998.

[26] H. Kusan, O. Autekin, and I. Ozdemir, "The use of fuzzi logic in predicting house selling price," Expert System Application, vol. 37, no. 3, 2010.

[27] Ş. Yalpir and G. Özkan, "Fuzzy logic methodology and multiple regressions for residential real-estates valuation in urban areas," Scientific Research and Essays, vol. 6, no. 12, pp. 2431-2436, 2011.

[28] J. Zurada, "Non-conventional approaches to property value assessment," Journal of Applied Business Research, vol. 22, no. 3, 2006.

[29] M. Renigier-Bilozor and R. Wisniewski, "The impact of macroeconomic factors on residential property prices indices in Europe," XLI Incontro di Studio del Ce.S.E.T, pp. 149-166, 2013.

[30] R. Wisniewski, "Modeling of residential property prices index using committees of artificial neural networks for PIGS, the European-G8, and Poland," Argumenta Oeconomica, vol. 1, no. 38, 2017. 
[31] L. Pi-Ying, "Analysis of the mass appraisal model," in Proceedings of the 23rd Pan Pacific Congress of Appraisers, Valuers and Counselors, San Francisco, Calif, USA, 2006.

[32] S. Peterson and A. B. Flanagan, "Neural network hedonic pricing models in mass real estate appraisal," Journal of Real Estate Research, vol. 31, no. 2, pp. 147-164, 2009.

[33] V.Limsombunchai, "House price prediction: hedonic price model vs. artificial neural network," in Proceedings of the NZARES Conference, Blenheim, New Zealand, June 2004.

[34] European Systemic Risk Board, "Vulnerabilities in the EU residential real estate sector," European System of Financial Supervision, 2016, https://www.esrb.europa.eu/pub/pdf/reports/161128_ vulnerabilities_eu_residential_real_estate_sector.en.pdf.

[35] Global Property Guide, "Residential property investment research," http://www.globalpropertyguide.com/.

[36] Deloitte, "Property Index-overview of European residential markets," Deloitte Czech Republic, 2016, https://www2.deloitte .com/content/dam/Deloitte/cz/Documents/survey/Property Index_2016_EN.pdf.

[37] S. Vanichvatana, "Thailand real estate market cycles: case study of 1997 economic crisis," GH Bank Housing Journal, vol. 1, no. 1, pp. 38-47, 2007.

[38] V. Rudzkienė and V. Azbainis, "Nekilnojamo turto rinkos evoliucijos pokyčiai pereinamosios ekonomikos sąlygomis," in Proceedings of the Business, Management and Education Conference Program, Vilnius Gediminas Technical University, Novemeber 2010.

[39] M. Burinskiene, V. Rudzkiene, and J. Venckauskaite, "Models of factors influencing the real estate price," in Proceedings of the 8th International Conference on Environmental Engineering, Vilnius Gediminas Technical University, Vilnius, Lithuania, May 2001.

[40] R. M. Valadez, "The housing bubble and the U.S. GDP: a correlation perspective," Journal of Case Research in Business and Economics, vol. 3, Article ID 10490, 2010.

[41] I. Johansen and R. Nygaard, "Owner-occupied housing in the Norwegian HICP,” Tech. Rep. 2009/18, Statistics Norway, Oslo, Norway, 2009.

[42] J. Clapp and C. Giacotto, "The influence of economic variables on house price dynamics," Journal of Urban Ecnomics, vol. 36, pp. 116-183, 1993.

[43] B. Grum and D. K. Govekarb, "Influence of macroeconomic factors on prices of real estate in various cultural environments: case of Slovenia, Greece, France, Poland and Norway," Procedia Economics and Finance, vol. 39, pp. 597-604, 2016.

[44] M. Mernagh, "House prices and unemployment: a story of linked fortunes," Significance in Economics \& Business, Royal Statistical Society and American Statistical Association, 2014.

[45] K. Sommer, P. Sullivan, and R. Verbrugge, "Run-up in the house price-rent ratio: how much can be explained by fundamentals?" Bureau of Labor Statistics, Working paper 441, 2011.

[46] J. Peek and J. A. Wilcox, "The baby boom, "pent-up" demand, and future house prices," Journal of Housing Economics, vol. 1, no. 4, pp. 347-367, 1991. 


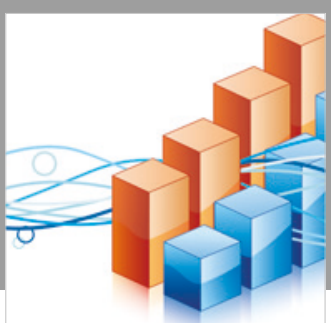

Advances in

Operations Research

\section{-n-m}
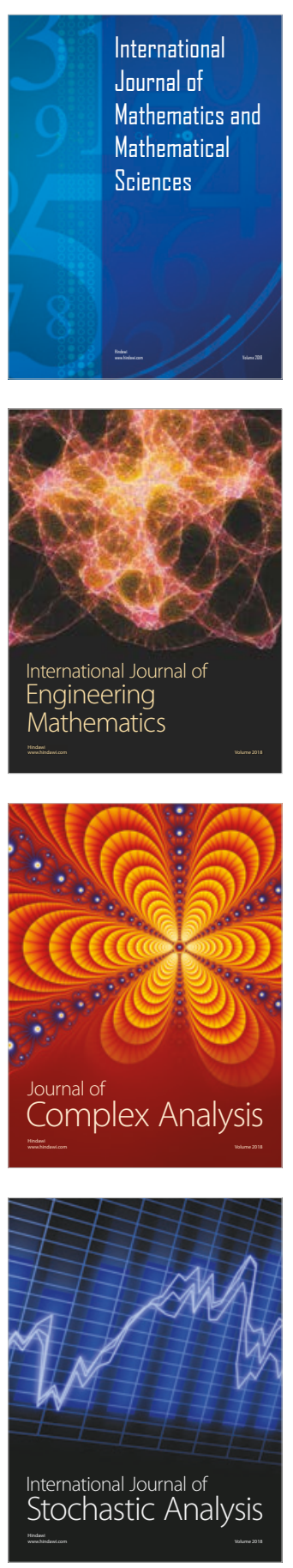
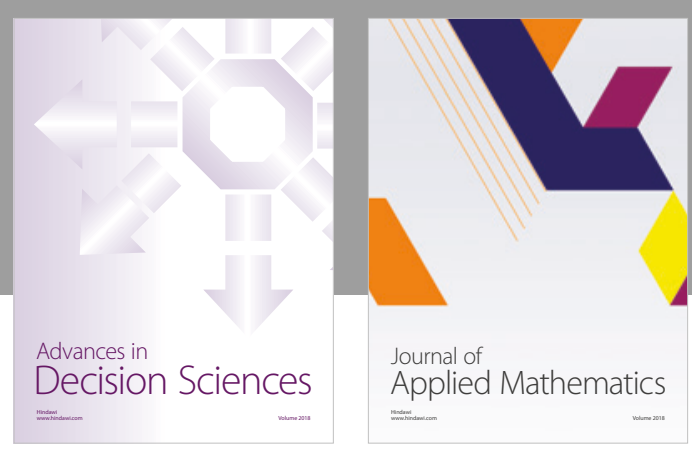

Journal of

Applied Mathematics
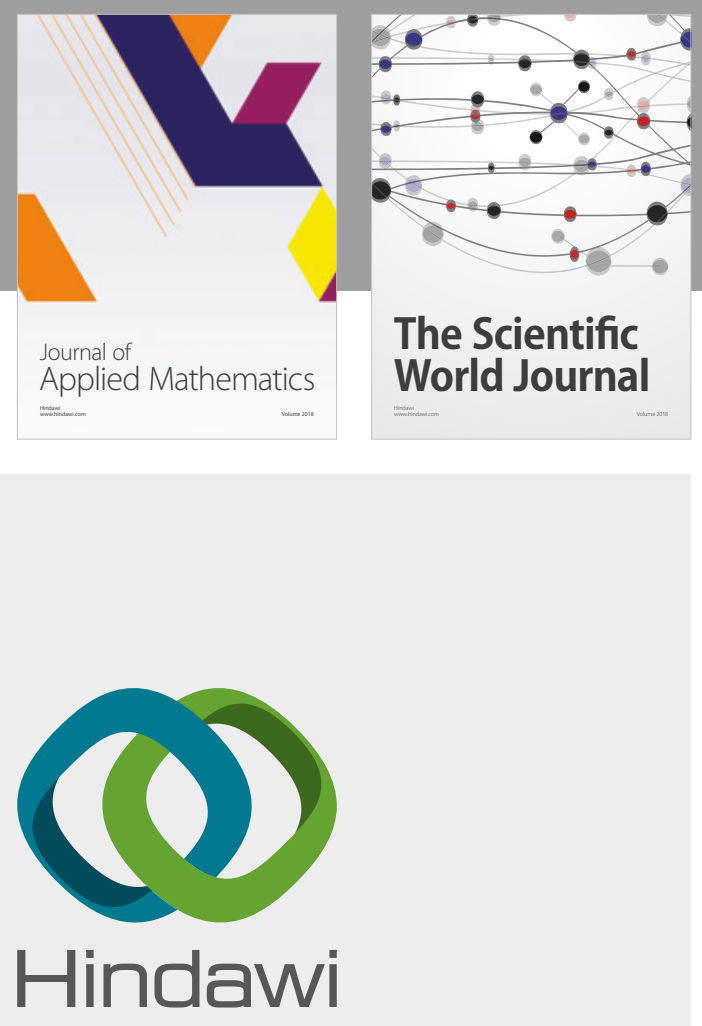

Submit your manuscripts at

www.hindawi.com

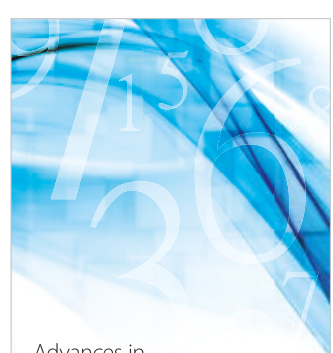

Advances in
Numerical Analysis
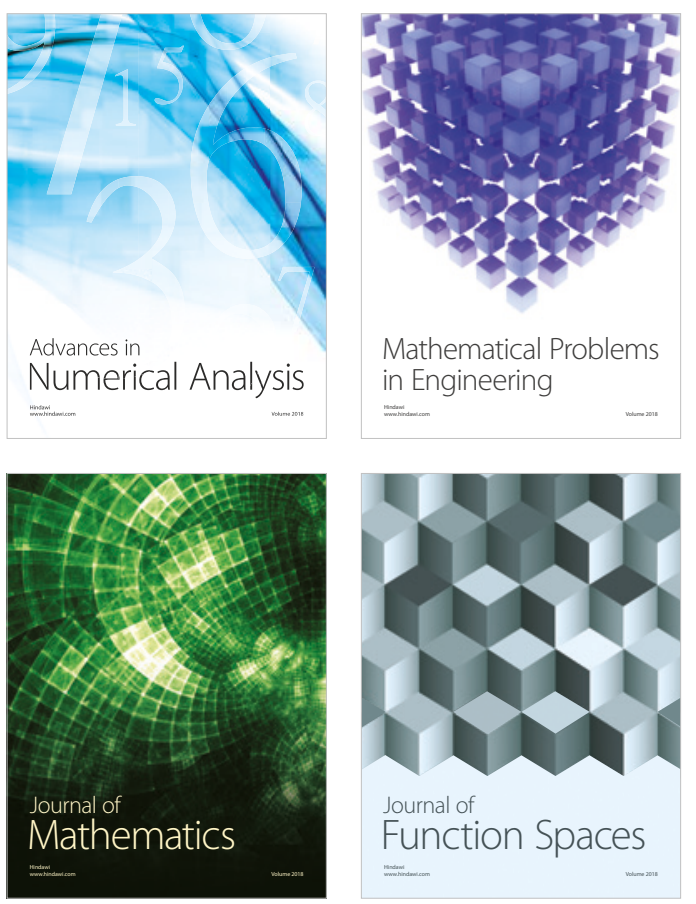

Mathematical Problems in Engineering

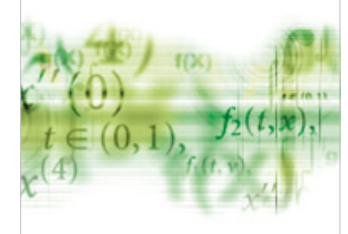

International Journal of

Differential Equations

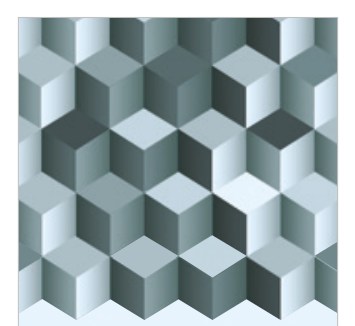

Journal of

Function Spaces
The Scientific

World Journal

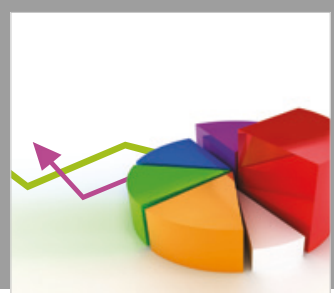

Journal of

Probability and Statistics
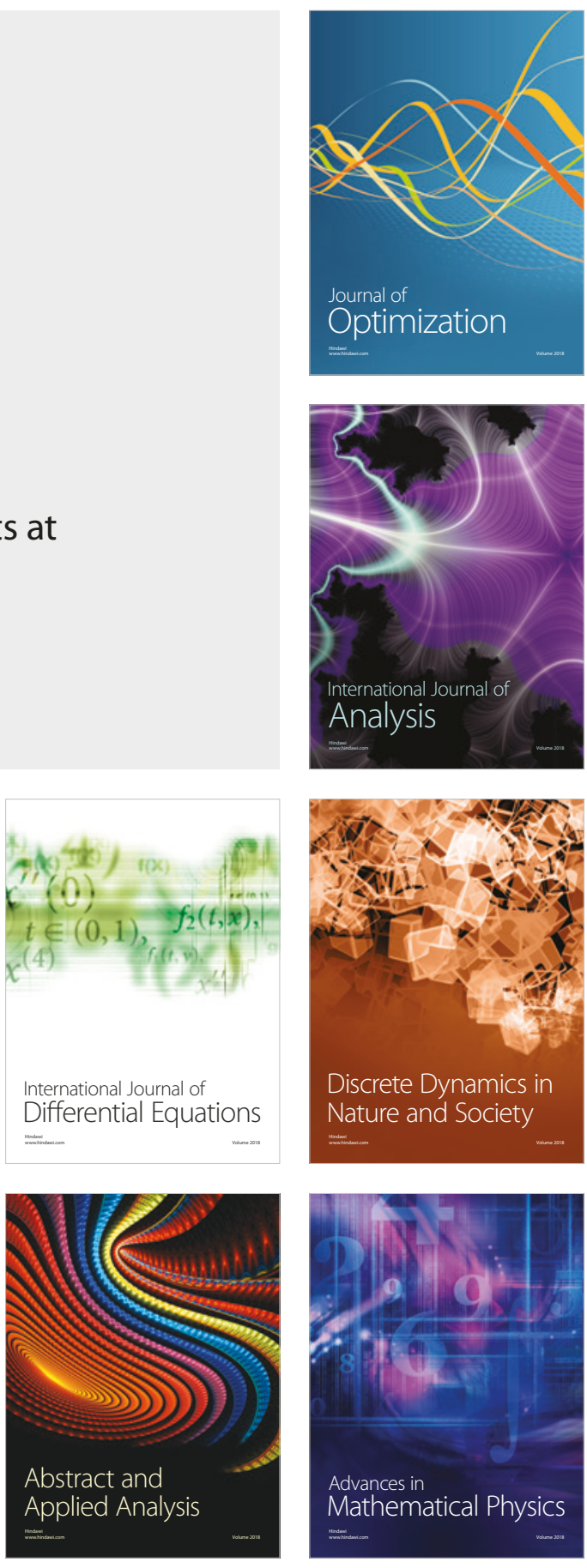